\title{
Diagnosis of Organizational Change: A multi-level approach (Case study of a French SME certified ISO 9001)
}

\author{
C.E.Mokhlis $^{1 *}$, A. Elmortada ${ }^{2}$, S.Marwane ${ }^{3}$ \\ ${ }^{1}$ Laboratory of Scientific Engineering of Organizations, Ecole Nationale de Commerce et de Gestion, \\ Hassan II University \\ ${ }^{2}$ Laboratory Process Signaux Système Industriel et Informatique \\ Cadi Ayyad university \\ ${ }^{3}$ Laboratory of Analysis Marketing and Strategic Organizations, Ecole Nationale de Commerce et de Gestion, \\ Hassan II University
}

\section{Article Info}

Received Jan 4, 2019

\section{Keyword:}

ISO 9001 standard

Strategic changes

Organizational changes

Organizational Learning

\begin{abstract}
Since their first certificates issued in 1989, ISO standards have grown considerably with, for example, more than $1,106,356$ certificates delivered in 2016 to ISO 9001 granted in the world [1].

Even though these standards have contributed significantly to the formalization of the company's knowledge, little is known about the consequences of implementing this framework in terms of organizational changes and learning dynamics. To better understand this phenomenon, we opted for a qualitative approach based on a single case study. Our approach attempts to consider several levels of analysis: organizational, strategic, cognitive and societal. Hence, we have used a model that superimposes these four levels to analyze the organizational changes that are induced by the implementation of the ISO 9001 management system, and their consequences on the modes of learning within a French SME.
\end{abstract}

Corresponding Author:

Chams Eddoha MOKHLIS

Departement of management,

Ecole Nationale de Commerce et de Gestion,

Hassan II University

2725 Route des Chaux et Ciments, Casablanca 20250, Morroco.

Email: chams.mokhlis@gmail.com

\section{Introduction}

The last three decades will undoubtedly still marked by the advent of quality as an advantage to conquer. During this period, a growing number of organizations around the world have invested in financial and human resources to comply with certification bodies' requirements for customer satisfaction.

Several companies, among them, have made a commitment to improving quality through certification ISO 9001. Indeed, according to the report published by the International Organization for Standardization (ISO) in September 2016, 1,106,356 ISO 9001certificates were issued in 184 countries. The phenomenon of global dissemination of this standard has also been cited in a large number of research works.

Despite their abundance, a lot of researches have focused on questions related to quality tools and methods but few studies have focused on understanding the changes induced by this standard. Moreover, works that studied the link between quality management practices and performance in its different dimensions are contradictory and inconclusive. A study led by Tzelepis [2] carrying on a sample of 1572 companies of three Greek manufacturing industries revealed that the certification according to the standard ISO 9001 reduces the productive ineffectiveness. Otherwise, Ullah [3] analyzed a sample of firms 21,852 firms of 31 Latin American countries and the Caribbean and underlined that the ISO certified companies show a 
productivity of the work superior and a clearly lower cost of the sales than the uncertified companies. In the same way, Aba and al [4] analyzed the operational performance for a sample of 397 companies certified of 1991-2002 and show that the certified companies had better results that those non-certified. On the contrary, the study led by Ilkay and Aslan [5] concerning a sample of 255 in turkey, demonstrates no statistically significant difference between certified and not-certified companies in terms of performance.

Thus, if some authors have found a positive link between ISO certification and performance: financial [4], commercial [6], other authors have shown that this link is negative [7], weak or nonexistent [5]. It should be noted that most of these studies remain reductionist, since each study deals with the impacts of quality approaches from a particular angle. Moreover, the majority of this work concerns the large companies. We consider, however, this approach as being restrictive. Thus we will try to propose a holistic approach that would allow a richer vision of the change process due to the certification processes.

Concretely, this approach would allow articulating cognitive, organizational, societal and strategic-economic levels of an organization. It also proposes analyzing the impact that the introduction of ISO 9001 quality management can have on its various levels by mobilizing The Lam model [8], extended by Lewkowicz [9]. The Mobilization of this model has the advantage of allowing the establishment of a synthetic diagnosis that takes into account variables which are rarely used by traditional methods of diagnosis.

We support the idea that learning and organizational change are now the only sustainable sources of a competitive advantage. It is precisely these analysis dimensions namely the organizational changes and learning mechanisms due to implementing of the ISO 9001 standard in SMEs context that we wish to deepen. This will lead us to state our research problem: To what extent can ISO 9001 certification transform an organization?

From this general question, other more specific questions are necessary:

What types of changes are they induced by this approach?

Does ISO 9001 promote or impede organizational learning?

Questioning the changes resulting from the ISO 9001 certification within companies leads to consider the conceptual framework of both the approach based on configurations and that of organizational learning. We propose to integrate these two perspectives in order to explain learning dynamics generated by implementing this reference within an SME.

State the objectives of the work and provide an adequate background, avoiding a detailed literature survey or a summary of the results.

\section{Theoretical framework}

\subsection{Approach Based on Configurations}

The configuration concept occupies a central place in the field of strategic management. It has a multitude of definitions, ranging from the perfect type to the gestalt, from coherence to archetype, to other denominations such as alignment, concordance or deep structure [10]

These expressions refer to any multidimensional association of conceptually distinct characteristics that are expressed together. The definitions of the configuration that have been proposed by the literature can be divided into two categories. First, configuration is defined as an integration of several endogenous and exogenous components. This integration is expressed in a set of multidimensional conceptual archetypes that have heterogeneous characteristics, and interfering with each other [11]. Secondly, other authors define it as the level to which the components of an organization are coordinated and assembled according to an interpretative scheme that constitutes a hardly decomposable dynamic system [12].

These definitions agree on two fundamental concepts to designate a configuration: the constituent elements (structures, strategies, environments, culture, systems, routines, etc.) and the interactions that keep them homogeneous.

The configuration approach was enriched by the founding works of Mintzberg [13], which are based on this same idea of coherence among the elements of design, but which consider organizational design as a state of the organization that is close of one of the ideal types. He first identified a typology of five organizational configurations: simple structure, mechanistic and professional bureaucracies, a divisional and adhocracy structure. Then, he later added two configurations: "missionary and politicized". These two configurations make it possible to take into account the phenomena of "corporate culture" and "power conflict". 
One of the main criticisms that can be addressed to Mintzberg's work is to limit the components of a configuration to the organizational level of analysis. Greenwood and Hinings [10] differentiate between the organizational and cognitive level. The cognitive level refers to the existing interpretative and alternative schemes that are more or less shared between the actors (individuals or groups). The organizational level is formed in relation to an environmental context and influenced by conflicts of interest.

In our research, we will emphasize the presence of an important split between the bureaucratic configurations, which are less favourable to change, and organic configurations (adhocracy) which are better suited to learning.On the other hand, Aoki [14] identifies the existence of a flexible configuration. This is the J-firm, or "typical Japanese firm". In contrast to the typical American firm: A, which is fairly well represented by the mechanistic bureaucracy.

\subsection{Organizational Learning}

The concept of organizational learning occupies a central place in academic fields and management practices. Indeed, several authors consider this as a prerequisite for maintaining the competitiveness of enterprises and for developing innovation [15].

Organizational learning is a complex concept that can be perceived from a wide variety of perspectives: Behaviorist orientation: learning is conceived as a behavioral adaptation, behavior change processes resulting from experiences [16] (Levitt \& March 1988). Cognitive orientation: learning is designed as a knowledge development, a process of changing the cognitive structure [17]. Social Orientation: learning occurs and knowledge is created mainly through conversations and interactions. According to this approach, organizational learning is attributed to collective construction by knowledge members [18].

In order to understand how the SME achieves an apprenticeship following the implementation of a quality approach, we will use the conceptual framework of the learning enterprise. ISO standardization will be analyzed here as a knowledge coding tool based on tacit knowledge [19] which is expressed in explicit and then formalized concepts. According to Nonaka [20], the creation of individual knowledge precedes the creation of organizational knowledge. His model postulates that the creation of organizational knowledge is the result of the interactions between tacit knowledge and explicit knowledge.They take the form of a dynamic and continuous cycle according to four modes of knowledge conversion, namely socialization (from tacit to tacit), outsourcing (from tacit to explicit), combination (explicit to explicit) and finally, internalization (from explicit to tacit).

On the other hand, learning theories consider that organizational change results from an evolution of organizational knowledge. This evolution involves the confrontation of ideas, favouring the challenge of preestablished patterns of thought, which implies a strategic change. Here we find the contribution of the configuration-based approach: learning capacity is influenced by the configuration, through the interactions that it stimulates or, on the contrary, that it prohibits.

Thus, from the point of view of organizational learning, strategic reflection comes down to a reflection on the organizational change to be implemented - in terms of configuration - to encourage learning. It remains to identify a framework that will allow the integration of these two perspectives of organizational change.

\subsection{The Extended Lam Model}

In order to analyze the organizational changes and the learning mechanisms induced by the integrating the ISO 9001 standard, we are based on the Lam model [8] that has been extended by Lewkowicz [9]. This framework integrates three major components of the literature: organizational learning theory, knowledge management and configuration-based approach.

In the continuity of the work of Mintzberg [13], Lam [8] postulates that the organizational structure is only one of the elements of a larger body which is the configuration. This later includes three levels: organizational level (crossing the degree of processes standardization with the individual or collective nature of the agent of essential knowledge), social level (crossing the external or internal call to the labour market with the degree of formalization of the educational system) and cognitive level (crossing both the epistemological dimension: tacit or explicit, and ontological dimension: individual or collective). This model identifies four "pure" configurations: mechanistic and professional bureaucracies, adhocracy [13], and J form organization [14]. These configurations are represented in Fig. 1. The author considers that each configuration is determined by an interaction between these three levels of analysis.

In addition, a strategic-economic component (crossing the type of business, inherited or sought after, with the type of shareholder valuation or partnership) is added to the interaction of the three original levels of the Lam 
model. The essential postulate of this model is that of an alignment between distinctive values taken by the four constituent elements. Each configuration is exposed, with the alignment of its supporting components, by one of the four quadrants of constituent elements. Each configuration is exposed, with the alignment of its supporting components, by one of the four quadrants of Fig. 1.

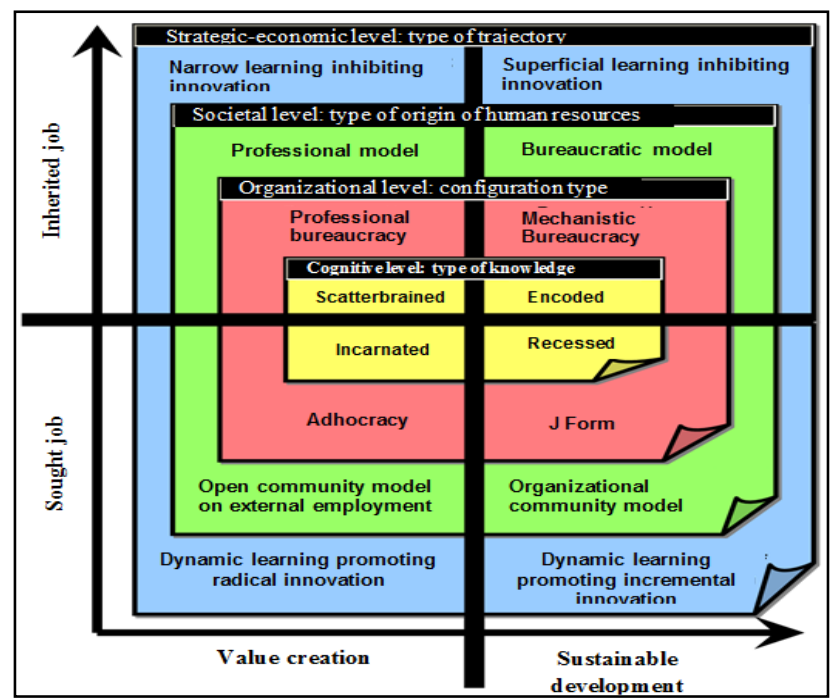

Figure1. Lam model (2000) extended by Lewkowicz (2006)

In short, Lam model extended by Lewkowicz [9], represents a descriptive typology but it can be used as a diagnostic tool for configuration. This can be useful to carry out an anticipated diagnosis of a prospective change. Since each configuration presupposes the alignment of specific values taken by the four components of the extended Lam model, misalignment Lewkowicz [21], refers to the situation where emerging events related to organizational decisions challenge pre-existing structures (cognitive, organizational, societal and / or strategic-economic structures) [22]. The configuration- based approach seems to be interesting to mobilize in our study because it contains a theoretical referential allowing diagnosis of the changes generated by introducing the ISO 9001 standard in organization.

\section{Research Methodology}

In order to meet our research objectives, we first adopted a qualitative exploratory study based on in-depth observation of a single case. It is a French SME operating in food industry, and certified according to ISO 9001 and ISO 22000 standards. Because of confidentiality reasons, this company will be described as "AMC". This choice was necessary for several reasons:

- This research strategy seems appropriate to our problem. Indeed, certification according to a standard is a change approach. Studying the impacts of such an approach requires direct contact with the executers in the field in order to better understand the underlying mechanisms. A unique case study is particularly recommended when dealing with complex fields of study where context-taking is critical to develop the understanding process [23].

- The principle of theoretical enrichment has largely guided our selection of the case. The latter was chosen for its "wealth of information" on the phenomenon studied. On one hand, it is a company which has three sites and which has a great diversity in terms of activities: collection, trading, drying and storage of cereals, Technical advice, services. On the other hand, this SME has achieved a good level of integration of the quality approach: it has been certified ISO 9001 (since 1997) and ISO 22000 (since 2007). This allows us to better understand the changes brought about by these standards. In the context of our study, the constitution of the sample responded to the need to contrast the individuals to the maximum in order to have differentiated visions of phenomenon under study. 


\subsection{Data Collection}

Several approaches were used to collect data: the conduct of $25 \mathrm{semi}$-directive interviews, we interviewed interlocutors of different hierarchical levels and with different functions. In order to understand the impact of ISO certification on the configuration, we used the Lam model extended by Lewkowicz [9]. As for the choice of observed variables, we relied on the observable variables mentioned in table (1).

Table 1. Observable variables mobilized for strategic diagnosis

\begin{tabular}{|c|c|}
\hline Level and dimension & Related variables \\
\hline $\begin{array}{l}\text { Cognitive - epistemic dimension } \\
\text { (Tacit / explicit knowledge) }\end{array}$ & $\begin{array}{l}\text { 1. Degree of formalization: (presence of procedures, systems } \\
\text { of knowledge integration...) }\end{array}$ \\
\hline $\begin{array}{l}\text { Cognitive - Ontological dimension } \\
\text { (Individual knowledge / collective knowledge) }\end{array}$ & $\begin{array}{l}\text { 2. Existence of mechanisms for information sharing } \\
\text { 3. Characteristics of the dominant organizational culture } \\
\text { (norms and values) } \\
\text { 4. Existence of professional and / or deontological standards }\end{array}$ \\
\hline $\begin{array}{l}\text { Organizational - dimension of standardization } \\
\text { level } \\
\text { (High standardization / low standardization) }\end{array}$ & $\begin{array}{l}\text { 5. Level of standardization of work processes and skills. } \\
\text { 6. Type of organizational structure }\end{array}$ \\
\hline $\begin{array}{l}\text { Organizational - level of autonomy } \\
\text { (Individual / organizational) }\end{array}$ & $\begin{array}{l}\text { 7. Possibility of initiative and personalization of work. } \\
\text { 8. Degree of flexibility of behavior in relation to procedures } \\
\text { (tolerance) }\end{array}$ \\
\hline $\begin{array}{l}\text { Societal - labor market dimension } \\
\text { (Open / internal) }\end{array}$ & $\begin{array}{l}\text { 9. Degree of Job Stability } \\
\text { 10. Possibility of hierarchical progression } \\
\text { 11. Type of labor market (internal / external) }\end{array}$ \\
\hline $\begin{array}{l}\text { Societal - dimension of educational system } \\
\text { (Degree of high / low formalization) }\end{array}$ & 12. Importance of academic training / acquired experience \\
\hline $\begin{array}{l}\text { Economic - dimension of trade nature } \\
\text { (Inherited trade / craft sought) }\end{array}$ & $\begin{array}{l}\text { 15. Degree of dependence of the organization on its } \\
\text { historical activities }\end{array}$ \\
\hline $\begin{array}{l}\text { Economic - dimension of valuation type } \\
\text { (Shareholder value / sustainable development) }\end{array}$ & $\begin{array}{l}\text { 17. Ethical position of the organization } \\
\text { 18. Nature of priority management indicators }\end{array}$ \\
\hline
\end{tabular}

\subsection{Data Analysis}

Interviews were recorded and transcribed manually. The analysis of the data was based on thematic analysis techniques based on unity of meaning. The themes that have emerged are: context and reasons for adopting the standard, method of its implementation, impacts of the ISO certification on the dimensions: cognitive, organizational, societal and strategic-economic of studied organizations, results obtained. We now present the results of the AMC company case analysis.

\section{Results and Discussion}

\subsection{Motivations and challenges related to the adoption of the ISO 9001 standard}

The decision to set up ISO certification within this company was voluntary. It is part of the Directorate's strategic choices in terms of improving customer satisfaction. During the interviews, two reasons were mentioned to explain the adoption of the standard: the main reason concerns the need to improve the internal organization of the company in order to satisfy its customers. The second reason is related to the need to formalize its know-how and to standardize the practices of its various services. We restore an inventory of the data collected and report on the analysis of the data.

\subsection{The influence of ISO9001 on the configuration: a multi-levels diagnosis}

We performed a multi-levels diagnosis of the AMC Company by mobilizing the extended Lam model. We propose a dynamic analysis of the changes induced by introducing ISO 9001 standards within this company. This approach reflects contingent evolutions between the initial structures (cognitive, 
organizational, societal, and strategic-economic) and impelled events (new and unexpected actions) by the quality approach.

This section is divided into four points: each point will situate the company AMC on the two dimensions structuring each of the levels. We propose to present the results of our diagnosis of the AMC case:

\subsubsection{Cognitive level:}

We have characterized the cognitive structures of this company by: - A strong and shared "Quality" culture, very consistent with the principles of the ISO standard. The implantation of this one generated a dynamics around the quality which reinforced this culture:

-"Historically, there was a strong culture of Quality Product; I had not a big difficulty sending messages because most people want to satisfy the customer" (chief executive officer)

A weak formalization of knowledge and a predominance of tacit and individual knowledge of some experts limited the opportunities for sharing and transferring it to other members of the organization as well as it increased its reliance on its core competencies. This Finding has been Raised by other Authors, who have pointed out that Tacit knowledge is associated with rigidity, since it is difficult to imitate, share and disseminate [24].

The changes observed since the introduction of the quality approach concerned the "slippage" of this undertaking from an oral culture to a culture of writing, which resulted in a massive codification and pooling knowledge. This effect was also underlined by the researchers who analyzed and interpreted the development of ISO standards in terms of increasing practices codification [25].

\section{- Results in terms of organizational learning}

At AMC, the ISO standard has played an important role in knowledge management. The implementation of this standard first served as a knowledge creation tool through its contribution to the conversion of knowledge, it also contributed to the importation of internal knowledge and good practices as well as those resulting from their codification and capitalization into a knowledge base. The repetitive application of procedures and work instructions increased the replicative capacity of the firm. Thus codified knowledge has been replicated by other members of the organization within other services. This has led to the introduction, over time, of organizational routines, which have led to the development of Learning by doing [26]. It is a procedural learning of different stages that lead to execute a process, an activity or a task:

- "Because of our decentralized sites, our employees are autonomous and implement skills that are essentially operational, they refer to the working instructions sheets when necessary" (Technical Manager)

On the other hand, and this is another lesson from our case study, the majority of respondents confirmed that the framework of ISO 9001 standard fostered a better understanding of the laws and principles that govern their business while allowing the accumulation of conceptual knowledge, particularly in the field of health risk control which in turn has allowed better practice in the analysis of these risks and broadened the potential range of services within the scope of business: - "The ISO framework helps to identify new standard solutions to suit changing customer and regulatory requirements" (Quality Manager)

Thus, the learning generated by the establishment of ISO within this company was more achieved by slow accumulation on the basis of existing routines than by breaks. This accumulated conceptual and operational knowledge has resulted in a strategic reorientation that AMC has implemented in the last two years while promoting safety control advising. From this point of view, the knowledge produced has stimulated a strategic reorientation to come:

-"The progressive integration of issues relating to the control of safety allowed us to develop expertise in this area that allows us to move towards advising farmers" (Deputy Director)

\subsubsection{Organizational level}

We relied on the work of the Aston school, and the researches of Kalika [27] to assess the characteristics of the organization. They suggest four main dimensions: formalization, standardization, specialization and centralization.

In the early years of its existence, the company's structure was simple [13]. The reduced staff of the latter favored informal collaboration; work coordination was based primarily on mutual adjustment and employees could more easily bind to each other and to the leader (charismatic leader). The authority was distributed on an oral and paternalistic way. Moreover, the gradual increase in company size and lengthening of the hierarchical structure necessitated his use of direct supervision and formalization of trade. 
- "The management of the company was done in a homely and very hierarchical way. As it is a small business, leaders controlled everything and wanted to know everything. It is still true today, but there are additional layers: they have grown together" (Human Resources Manager)

Moreover, the consultation of the various versions of the flow chart of the company shows a strong vertical and horizontal specialization: before the certification, the company regrouped several functions and had more than five hierarchical levels. The leaders focused almost all of the powers. However, coordination problems between different sites have emerged gradually with the development of the company and have necessitated the establishment of standardization. The use of the quality approach was described by respondents as an opportunity to organize the company to cope with its growth:

- "The more the organization grows, the more it was important to adopt procedures. The increased number of employees made the existing informal procedures inoperative. We had then to formalize ways to act through procedures "(Quality Manager)

Similarly, various forms of written documents formed an organizational memory. But this memory lacked structure. ISO has brought this structure. Indeed, the introduction of the ISO reference within this business was accompanied by an increased formalization of exchanges and practices; on the other hand, a standardization of work processes through process descriptions, procedures and functions sheets has also been taken into consideration. We can thus talk about moving from a personal type of control to control based on standardizing processes. The knowledge agents are neither workers nor managers but they are the persons in charge of techno-structure (Quality responsible and experts) who conceived the rules and guided its implementation. Strengthening the standardization of the entire organization does not exclude the existence of significant differences between the different services. The activity analysis revealed that the logistics, control and accounting seemed to be the most standardized, while the services of: purchase, sales and personnel have lower levels of standardization. These differences can be explained by the weight of legal and regulatory constraints, the nature of work and the importance of negotiating inside of the service activity [27].

The implementation of this standard was also accompanied by a clarification of work division and increased specialization and control. The changes in terms of structure concern: the allocation of additional resources to implement the quality policy such as appointing trained internal auditors. As for the control, it was intensified by the introduction of new devices such as monitoring performance indicators.

Furthermore, if the centralization of decisions in the hands of the three leaders remains strong, promoting the specialization and the introduction of a planning and control system has favored a relative decentralization of decisions.

In addition, significant changes were found concerning work organization: these include among others: the development of teamwork, self-monitoring practices and empowerment of employees, the establishment of participatory structures such as inter-silo quality improvement teams and problem solving groups, the establishment of mechanisms for collecting and reassembling the improvement proposals to the leaders.

Thus as illustrated by the Quality Manager, quality approach was seen as a factor likely to change the management style of the company:

-"The management style has evolved to move toward more participatory: There were meetings which brought together managers. But there were never any meetings that included operators, employees and managers: it was a revolution».

By giving executers the opportunity to participate in drafting procedures and rules, the standard implies that rather than autonomy to mean action space where the performer can choose between alternatives, but in a dependent environment.

- "Often the margin of employee maneuver is delimited in their function definitions; there are procedures to follow in case of problems in their trades. Those are described in outline and it is for them to meet these lines. Then, if they are in the margin over the outline inevitably, they must be validated by the management office "(Human Resources Manager)

However, despite the implementation of certain participatory structures, the development of self-monitoring practices and employee empowerment, It emerges that autonomy and delegation of authority tend to grow, but without undermining the hierarchical control nor power relations:

-"The ISO has promote the participative management in our company, but it remains very strongly hierarchical. Within our firm, if you go to meet a subordinate without informing the head chief, you will have a negative feedback "(Logistics Manager) 


\subsubsection{Societal level}

The diagnosis at the societal level reveals some structural characteristics: the formalization degree of education was low, academic qualifications and skills acquired through practice enjoyed equal recognition at recruitment. The latter was open to both young graduates and to persons who have professional experience that is not validated based on a diploma. The prerequisites required by functions were not formalized.

Moreover, the expertise accumulated within the firm through practical experience were valued and recognized as a basis for promotion, which promoted the transmission and mobilization of tacit knowledge.

- "Within silos, simple employees were able to climb the ranks and become team leaders. They even become heads of department" (Warehouse Manager)

Regarding the labor market, it was essentially opened to the outside employment: local companies form a network where employees can evolve.

Overall, based on the cited arguments, diagnosis of structures at the societal level defines the organization as a model of an opened community to the outside employment. It is characterized by the predominance of an opened system to the outside employment which combines formal education and practical experience, a system where the required skills are few formalized, tacit knowledge is valued and intermediate skills are well represented.

Opening to external recruitment favored the import of external knowledge to broaden the company's knowledge base. Formalization of the requirements of each position was the basis for targeting the desired profiles when recruiting. To define the profiles, the company relied heavily on business standards that include the occupation of standard practices which led to qualifications as well as to a standardization of both skills and profiles: "The skills required for a position are clearly formalized in job descriptions. This tool was created with the ISO; it did not exist before" (Human Resources Manager)

The quality approach has led to a standardization of skills through standardization of practices and qualifications, the formalization of job descriptions and training. Formal knowledge, are more valued and tacit knowledge is less used. If this standardization limited the variety and diversity of profiles, it favored the versatility, mobility and the use of the internal market.

In sum, at the societal level, the events recorded since introducing the standard tend to distance the organization from the opened community model in order to be closer to the bureaucratic model.

\subsubsection{Strategic-economic level}

We asked our respondents on the existence and definition of a strategy within their business, if the unanimity said that a strategy was defined, they argue that it was implicit: "Before ISO there was certainly a well-defined strategy but it was not formalized" (Director of operations)

The implicit characteristic of the strategy essentially results in low number of planning and control devices. According to respondents, the company had neither explicit nor political plans; its budget system was underdeveloped. Except commercials, services had no explicit objectives and even when these were formalized, they were mainly economic. But that does not mean there was no control, quite the opposite direction realized a direct and almost daily supervision services.

Moreover, the remarks of respondents indicate that the organization seems to be like a model for exploitation as March affirmed [28]: It is based on optimization, efficiency and upgrading existing skills

-" Collection, drying, storage, cereals marketing and sale of fertilizers as well as plant protection products represent the main business that our company operates since the 1950s" (Deputy director)

Indeed, the company's business comes from its historical object. This is an inherited profession that the company operates and seeks to develop since several years.

Based on this analysis, we can conclude that the structures at the strategic level reveal a low formalization of the strategy, a limited use of planning systems and control procedures. These only concerned the management control. But if it does not mean that there was no control, we have shown that to overcome the lack of explicit objectives and forecasts, management realized almost daily direct supervision on Services.

As for the business type we were able to distinguish strong indications that place the company on a legacy business. Finally, the type of regulation is clearly focused on creating shareholder value. This results in the presence of exclusively economic objectives.

The changes observed since the introduction of the standard, at the strategic level, concern particularly the strategy formalization. Indeed, responses analysis shows that the quality of the process is involved in defining 
the strategy by helping to clarify the goals and missions of the organization but is not a substitute for exercising the strategic development.

- "Customer satisfaction approach is the basic foundation of the company's strategy since its creation. Everything is structured around its aspects with a central goal which is of conquering new industries and retains the existents" (Silo Moderator)

Once the company's strategic priorities have been defined and the quality policy has been established, the quality process contributed to the deployment of these guidelines into objectives and action plans. Thus, the implementation of standardization was also accompanied by a strengthening of planning systems and control tools. The quality process organized control through its generalization on all processes and providing measurement logic through diverse indicators. The creation of shareholder value is no longer the only performance indicator.

In addition, our investigations point out that the ISO 9001 provided a framework that promote taking into consideration environmental and social aspects of sustainable development. This is materialized by the implementation of various actions in these areas: "Since the appearance of the quality approach in 1997, the company has diversified its activities in the field of sustainable development. Moreover, these actions were primarily driven by the quality department" (Operations Manager).

Although the exploitation of existing activities and exploring new opportunities were two strategies simultaneously addressed by this company, the organization is closer to an operating model [28] that to an inherited trade that it seeks to enhance through developing its distinctive capabilities while optimizing its resources.

All these elements suggest that the company has grown from a type of regulation that favors shareholders (Shareholders value approach) to a type of regulation by the stakeholder value. However our study tends to nuance this observation. The speech analysis reveals the gap between the importance accorded to sustainability issues and the lack of implemented actions by the company to face them.

- "Economic sustainability is the first concern for leaders and managers, secondly the environmental aspect and thirdly the social level" (Financial Director)

If this analysis shows that the social dimension is poorly considered, it is interesting to note that the actions of this company in favor of integrating the environment are primarily motivated by regulatory issues to demonstrate the organization conformity to the legal framework governing their activities.

Overall, even if sustainable development was omnipresent in Director and managers' speech, response analysis shows that they seek above all to improve the economic performance of their business. Their investment in environmental actions has been done for strengthening the institutional legitimacy of their organization. If this concern for legitimacy has not been cited as the main promoter of standard implementation within the company, analysis of different sources of collected data reveals that it was not that absent complement.

Table2. Results Summary of AMC diagnosis

\begin{tabular}{|l|l|l|l|}
\hline Dimension & structures & Events & Change nature \\
\hline \multirow{4}{*}{ Cognitive } & Culture, High quality & Culture enhanced Quality & Enhancement \\
\cline { 2 - 4 } & Individual tacit knowledge & $\begin{array}{l}\text { Implementation of knowledge transfer } \\
\text { mechanisms (meetings, knowledge } \\
\text { bases) }\end{array}$ & Breaking \\
\hline \multirow{5}{*}{ Organizational } & Low formalization & Increased formalization, but structured & Breaking \\
\cline { 2 - 4 } & Direct supervision & High standardization & Breaking \\
\cline { 2 - 5 } & High specialization & Enhanced specialization & Enhancement \\
\cline { 2 - 5 } & Well hierarchical control & Formalized and intensified control & Enhancement \\
\cline { 2 - 5 } & High centralization & Slight Decentralization & Slight changes \\
\cline { 2 - 5 } & Directive management & $\begin{array}{l}\text { Introduction participatory practices of } \\
\text { management }\end{array}$ & Slight changes \\
\cline { 2 - 5 } & Partitioned services & Persistent Problems of coordination & Continuity \\
\hline
\end{tabular}


PENVol. 7, No.2, August 2019, pp.932-943

\begin{tabular}{|l|l|l|l|}
\hline & & between functions & \\
\hline \multirow{5}{*}{ Societal } & $\begin{array}{l}\text { Low formalization } \\
\text { of skills }\end{array}$ & $\begin{array}{l}\text { High formalization and standardization } \\
\text { of skills }\end{array}$ & Breaking \\
\cline { 2 - 4 } & External employment & $\begin{array}{l}\text { Integrating the internal market, but } \\
\text { dominance of external employment }\end{array}$ & Slight changes \\
\cline { 2 - 4 } & $\begin{array}{l}\text { Non-elitism } \\
\text { Valuation of tacit knowledge }\end{array}$ & $\begin{array}{l}\text { Valuation of academic knowledge at the } \\
\text { expense of tacit knowledge }\end{array}$ & Breaking \\
\hline \multirow{5}{*}{$\begin{array}{l}\text { Strategic- } \\
\text { Economic }\end{array}$} & Low formalized strategy & Formalization of the strategy, & Breaking \\
\cline { 2 - 5 } & $\begin{array}{l}\text { Low use of and } \\
\text { planning and control system }\end{array}$ & $\begin{array}{l}\text { Strengthening planning } \\
\text { formalization of control }\end{array}$ & Breaking \\
\cline { 2 - 5 } & $\begin{array}{l}\text { Operating an inherited } \\
\text { profession }\end{array}$ & Operating an inherited profession & Continuity \\
\cline { 2 - 5 } & $\begin{array}{l}\text { Creating only shareholder } \\
\text { value }\end{array}$ & $\begin{array}{l}\text { Integration of social and environmental } \\
\text { dimensions of sustainable development }\end{array}$ & Breaking \\
\hline
\end{tabular}

\section{Conclusions}

It was difficult to define the starting configuration of the organization in a specific quadrant: cognitive structures resulting from an adhocracy, organizational structures corresponding to the mechanistic bureaucracy model, societal structures resulting from the model of open community regarding the external employment, organizational structures resembling to March model [28], with a recovery focused on creating shareholder value.

The evolution observed since the introduction of ISO 9001 concerns mainly the formalization development, the standardization and the enhancement of both specialization and control. However, being taken apart from these issues, ISO 9001 has not brought a radical change.

The ISO standard has attempted to introduce in this business some practices of participatory management, however, its implementation has generated a strengthening of control devices at the warehouses. Empowerment does not cause a change in power relations within the company but may paradoxically generate an increase in their subordination to the current standards and strengthening the social distance between different hierarchical levels [29] Thus, despite the organizational changes introduced since the launch of the certification in 1996, the AMC structure remains strongly hierarchical and compartmentalized that conserves the characteristics of the mechanistic bureaucracy [13]. If the aim of improving the internal organization explains in a large measure the decision of the executive to adopt the standard, we have noted that the introduction of this standard has been accompanied by a strengthening of bureaucratic structural features. ISO standard therefore included a significant risk: to cause a multi-level change that is different from the strategic change desired by its initiators.

We could identify some brakes that may explain why the quality approach has not achieved the desired effect: - Managerial constraints: On one hand, there is a deep discrepancy between the chief executive officer's visions: "control" orientation and the way in which the project was presented to employees: oriented towards "personal development". On the other hand, the involvement of site managers in the process is gradually losing steam, which contributes to a loss of benchmarks for employees.

- Organizational and contextual constraints : we have concluded that the rationality of the norm has led to some perverse effects that characterize the rational myths : to make employees aware of continuous improvement without fundamentally changing the motivation system, - Develop commitment to the organization's objectives without changing the way income is distributed, - Promote continuous learning and encourage employees to propose ideas for improvement while asking them to comply with procedures and standardized practices, - Encourage employees to take training in empowerment techniques so that they can participate in the achievement of collective goals and increase their responsibilities without calling into question Top-Down's hierarchical control.

To these effects already raised by the study by Hackman and Wageman [30], other limitations were also revealed by our study: the negative perception of the real utility by some actors, quality management procedures, the difficulties to be set to in a multi-criteria dimension of value (customer, shareholder, societal, etc.). This limitation, inherent in the question of multicriterion assessments, can result from the proliferation during these last years of contradictory and sometimes incompatible norms. 
Our study reveals the relevance of the quality critical current in terms of analyzing the discrepancies observed during the implementation of a quality approach between what is advocated and conveyed by mangers speech and specialized consultants in quality in comparison to practices realities in this field. These works attempt to question the normative and prescriptive approach that has long dominated the literature on the theme of quality. For them, quality management is not necessarily a stimulus for staff involvement and it does not promote the creation of a meaningful economic value [29]. They advocate "opening quality management to new perspectives in order to allow critical evaluation and holistic understanding of quality approaches" [31]. In short, the mobilization of the Extended Lam Model has the advantage of making possible to establish a synthetic diagnosis of the changes generated by introducing the ISO 9001 standard while taking into account variables that are rarely mentioned in traditional methods of diagnosis.

The limitations of this research raise the need to generalize the results of our research. The first proposed idea would be to extend the search to a larger sample in order to strengthen the external validity of our research.

\section{References}

[1] The ISO survey of management system standard certifications, 2015.

[2] D.Tzelepis,K.Tsekouras, D.Skuras and E. Dimara, "The effects of ISO 9001on firms productive efficiency", International Journal of Operations \& Production Management, vol.26, pp:1146-1165, 2006.

[3] B.Ullah, Z. Wei and F. Xie, "ISO certification, financial constraints, and firm performance in Latin American and Caribbean countries", Global Finance Journal, vol.25, pp: 203-228, 2014.

[4] E.K. Aba, M.A. Badar and M.A. Hayden, "Impact of ISO 9001 certification on firms financial operating performance", International Journal of Quality \& Reliability Management, vol. 33, pp: 78-89, 2016.

[5] M.S. İlkay, E. Aslan, "The effect of the ISO 9001 quality management system on on the performance of SMEs", International Journal of Quality \& Reliability Management, vol: 29, pp: 753-778, 2012.

[6] J.Qijun, and P.J.Batt, "Barriers and benefits to the adoption of a third party certified food safety management system in the food processing sector in Shanghai, China", Food Control, vol: 62, pp: 89-96. 2016.

[7] O. Boiral, "ISO 9000, Outside the Iron Cage", Organization Science, vol: 14, pp: 720-737, 2003.

[8] A.Lam, "Tacit knowledge, Organizational Learning and Societal Institutions: An Integrated Framework Organization Studies", Organization Studies, vol : 21, pp: 487-513, 2000.

[9] J.Lewkowicz, "Vers une synthèse des niveaux cognitif, organisationnel, sociétal et économique en matière de diagnostic stratégique", Actes du colloque international: "Développement organisationnel et changement", ISEOR, 2006.

[10] R.Greenwood and C.R. Hinings, "Understanding strategic change: the contribution of archetypes. Academy of Management Journal", vol : 36, pp: 1052-1081, 1993.

[11] J.P.Meyer, L. Herscovitch, "Commitment in the Workplace: Toward a General Model", Human Resource Management Review, vol. 11, pp. 299-326, 2001.

[12] D. Miller, "Configurations revisited", Strategic Management Journal, vol : 17, pp: 505-512, 1996.

[13] H. Mintzberg, " Structure et dynamique des organisations”, Editions d'organisation, Paris, 1982.

[14] M.Aoki, "Horizontal vs. Vertical Information Structure of the Firm", American Economic Review, vol.76, pp. 971-983, 1986.

[15] I.Nonaka and H. Takeuchi, "The Knowledge-Creating Company: How Japanese Companies Create the Dynamics of Innovation", Oxford University Press, New York. 1995.

[16] B.Levitt and J. G. March, “Organizational Learning”, Annual Review of Sociology, vol: 14, pp: 319-338, 1988.

[17] C. Argyris and D. A. Schön, "Apprentissage organisationnel : théorie, méthode, pratique", De Boeck Université, Paris, 2002.

[18] A.M., Lamsa and S. Teppo, "A narrative approach for organizational learning in a diverse organization", Journal of Workplace Learning, vol : 17, pp: 106-120, 2006.

[19] M.Polanyi, “The Tacit Dimension”, Anchor Day, New York, 1966. 
[20] I.Nonaka, “A Dynamic Theory of Organizational Knowledge Creation”, Organization Science, vol: 5, pp: 14-37,1994.

[21] J.Lewkowicz, P. Koeberle, "Le développement durable est-il durable ? L'impact de l'interdépendance des composantes cognitive, organisationnelle, sociétale et économique", Innovations, vol : 1, pp. 9-33, 2009.

[22] N.Fairclough, "Peripheral vision: Discourse analysis in organization studies: The case for critical realism", Organization Studies, vol: 26, pp: 915- 939, 2005.

[23] R.K. Yin. Case Study Research: Design and Methods (4th Ed.). Thousand Oaks, CA: Sage, 2009.

[24] I.Daugule and A. Kapenieks, "Knowledge flow analysis: the quantitative method for knowledge stickiness analysis in online course," Periodicals of Engineering and Natural Sciences, vol. 7, pp.165$171,2019$.

[25] CE.Mokhlis, “Absorptive Capacity and Organizational Learning: Application to five French companies in the health biotechnology sector", Doctoral Thesis in Management, under the direction of Jacques Liouville, University of Strasbourg, EM Strasbourg Business School, 580 p, 2014.

[26] D. Bērziña, "Learning by doing. Case study: education for sustainable development at the University of Latvia", Periodicals of Engineering and Natural Sciences, vol. 7, pp.156-164, 2019.

[27] M. Kalika, "Structures d'entreprises: réalités, déterminants, performances", Economica, 1995.

[28] J. G. March, "Exploration and Exploitation in Organizational Learning", Organization Science, vol. 2, ${ }^{\circ}$ 1, pp. 71- 87, 1991.

[29] J. Igalens, Dhaoudi, El Akerimi, "Une analyse critique du Management par la qualité totale : implications pour la GRH", Revue de gestion des ressources humaines, P.2-22, 2008.

[30] R.J. Hackman, Wageman, “Total Quality Management: Empirical, Conceptual, and Practical Issues". Administrative Science Quarterly, pp: 309-342, 1995.

[31] F. Mueller, C.H. Carter, "The scripting of total quality Management within its organizational biography", Organiszations studies, Vol: 26, pp: 221-247, 2005. 